\title{
Obstrüktif Uyku Apne Sendromu ile Kardiyovasküler Hastalıklar Arasındaki İliş- kiyi Gösterebilecek Tam Kan Sayımı Değerleri
}

\section{Complete Blood CountValuesthat May Show the Relationship Between Obstruc- tive Sleep Apnea Syndrome and Cardiovascular Diseases}

\author{
Buket MERMIT ÇILİNGİR (D)*
}

Atıf Yapmak İçin: Mertmit Çilingir B. Obstrüktif Uyku Apne Sendromu ile Kardiyovasküler Hastalıklar Arasındaki İlişkiyi Gösterebilecek Tam Kan Sayımı Değerleri. Van Sag Bil Derg 2021, 14,(3) 338-345. https://doi.org/10.52976/vansagl ik.979551.

Geliş Zamanı:06/08/2021

Kabul Zamanı:26/12/2021

Basılama Zamanı: 30/12/2021
1 Van Yüzüncü Yıl Üniversitesi Tıp Fakültesi, Göğüs Hastalıkları A.D, Van, TÜRKİY.

* Sorumlu yazar: Buket MERMIT ÇİLINGİR;.E-mail:buketmermitcilingir@gmail.com.

\section{ÖZET}

Amaç: Obstüktif Uyku Apne Sendromu'nda kardiyovasküler hastalıklar platelet aktivasyonu ve inflamasyonun rol aldığı bir süreç ile gelişir. Platelet aktivasyonu ve inflamasyonu ise Eritrosit Dağılım Genişliği(EDG), Trombosit Dağılım Aralığı(TDA) ve Ortalama Trombosit Hacmi(OTH) parametreleri gösterebilir. Bu çalışmada OUAS hastalarında, kolay ulaşılabilen, maliyeti düşük bir değerlendirme olan tam kan sayımı kullanılarak EDG, TDA, OTH değerleri ile eşlik eden kardiyovasküler hastalıklar arasındaki ilişkinin değerlendirilmesi amaçlandı.

Materyal ve Metot: Polisomnografi ile OUAS tanısı alan hastalar AHI (Apne Hipopne İndeksi) skorlarına göre sinıflandırıldı. Grup A: basit horlama(AHI<5), Grup B: hafif(AHI:5-14,9), Grup C: orta(AHI=15-30) ve Grup D:ağır(AHI >30) OUAS olarak tanımlandı. Tam kan sayımı sonuçlarından EDG, TDA ve OTH değerlerine bakild1.

Bulgular: 140 hastanın dahil edildiği çalışmada hastalar 18-78 yaş arasındaydı. TDA, EDG, OTH, hemoglobin $(\mathrm{Hb})$ ve Hematokrit $(\mathrm{Htc})$ değerlerinde hastalık ağırlığı ile ilişkili bir değişiklik saptanmadı $(\mathrm{p}>$,05). Sigara içiciliği, Diyabet(DM), Hipertansiyon(HT), Kardiyovasküler Hastalık(KVH) varlığı ile TDA, EDG ve OTH arasında istatistiksel olarak anlamlı bir ilişki yoktu. Ortalama ve en düşük Oksijen saturasyonu değerleri ağır OUAS grubunda en düşük düzeydeydi $(\mathrm{p}<, 05, \mathrm{p}<, 001)$. ODİ (Oksijen Desaturasyon İndeksi) Grup A'da 9,9 $\pm 13,7$ ile en düşük değerde iken, AHİ arttıkça giderek arttığı $(9,8 \pm 10,3 ; 19,5 \pm 18,3 ; 41,0 \pm 24,0)$ belirlendi $(\mathrm{p}<0,001)$. Ağır OUAS grubunda Hipertansiyon görülme oranı diğer gruplardan istatistiksel olarak anlamlı düzeyde yüksekti $(\mathrm{p}=0,025)$. HT görülen OUAS hastalarında ortalama ve en düşük oksijen saturasyonu istatistiksel olarak daha düşük (p: ,025, p: ,004) ODİ ise istatistiksel olarak daha yüksekti (p=,004). KVH ve DM görülme oranı da ağır OUAS grubunda daha fazlaydı ancak istatistiksel olarak bu fark anlamlı değildi.

Sonuç: Çalışmamızda OUAS'a eşlik eden kardiyovasküler hastalıklar ile EDG, TDA VE OTH arasında bir ilişki saptanmadı. AHİ ve ODİ yükseldikçe, ortalama ve minimum oksijen saturasyonu düștükçe eşlik eden hastalıkların varlığında artış gözlendi. Bu bulgular bize OUAS'da KVH'ların görülmesinde asıl sebebin hipoksi ve ilişkili mekanizmalar olduğunu düşündürmektedir. Bu konuyu araştırmak için hasta sayısının daha çok olduğu ve basınç tedavi sonrası gözlemleri de içeren daha geniş kapsamlı çalışmalar yapılması gerekmektedir.

Anahtar Kelimeler: Obstrüktif Uyku Apne Sendromu, Eritrosit dağılım genişliği, Trombosit dağılım aralı̆̆ı, Ortalama trombosit hacmi, Kardiyovasküler hastalıklar.

\section{ABSTRACT}

Objective: Cardiovascular diseases in Obstructive Sleep Apnea Syndrome develop with a process in which platelet activation and inflammation play a role. Platelet activation and inflammation can show Red Cel Distribution Width (RDW), Platelet Distribution Width (PDW) and Mean Platelet Volume (MPV) parameters. In this study, it was aimed to evaluate the relationship between RDW, PDW, MPV values and concomitant cardiovascular diseases by using complete blood count, which is an easily accessible and low cost evaluation in OSAS patients.

Material and Method: Patients diagnosed with OSAS by polysomnography were classified according to their AHI (Apnea Hypopnea Index) scores. Group A: simple snoring (AHI<5), Group B: mild (AHI:5-14.9), Group C: moderate (AHI=15-30) and Group D: severe (AHI >30) OSAS. RDW, PDW and MPV values were checked from the results of the complete blood count.

Results: In the study, which included 140 patients, the patients were between the ages of 18-78. There was no change in PDW, RDW, MPV, hemoglobin $(\mathrm{Hb})$ and Hematocrit $(\mathrm{Htc})$ values related to disease severity ( $\mathrm{p}>.05)$. There was no statistically significant relationship between the presence of smoking, Diabetes(DM), Hypertension (HT), Cardiovascular Disease(CVD) and RDW, PDW and MPV. The mean and lowest Oxygen saturation values were lowest in the severe OSAS group ( $p<.05, p<.001)$. While ODI (Oxygen Desaturation Index) was the lowest in Group A with 9.9 \pm 13.7 , it gradually increased as AHI increased $(9.8 \pm 10.3 ; 19.5 \pm 18.3 ; 41.0 \pm 24,0)$ was determined $(p<0.001)$. The incidence of hypertension in the severe OSAS group was statistically significantly higher than the other groups $(\mathrm{p}=0.025)$. In OSAS patients with HT, mean and lowest oxygen saturation was 
statistically lower (p: .025, p: .004), while ODI was statistically higher ( $\mathrm{p}=.004)$. The incidence of CVD and DM was also higher in the severe OSAS group, but this difference was not statistically significant. Conclusion: In our study, no relationship was found between cardiovascular diseases accompanying OSAS and RDW, PDW, and MPV. As AHI and ODI increased and mean and minimum oxygen saturation decreased, an increase was observed in the presence of concomitant diseases. These findings suggest that the main reason for the occurrence of CVD in OSAS is hypoxia and related mechanisms. In order to investigate this issue, more comprehensive studies with a larger number of patients and including post-pressure treatment observations are required.

Keywords: Obstructive Sleep Apnea Syndrome, Red cell distribution width, Platelet distribution width and mean platelet volume, Cardiovascular diseases.

\section{GİRİ̧̧}

Obstrüktif Uyku Apne Sendromu (OUAS) uyku esnasında üst solunum yollarının tam veya kısmi tıkanma atakları ve soncunda oksijen saturasyonunda düşme ile karakterize bir hastalıktır (ICSD-2, 2005). Türkiye'de OUAS prevalansının\%0.9-1.9 arasında olduğu bildirilmiştir. Hastaların \% $4^{\prime}$ ünü erkek, \%2'sini kadınlar oluşturmaktadır (Köktürk ve ark., 1997). Horlama, tanıklı apne, gündüz aşırı uykululuk hali gibi belirtileri ile başvuran hastada uyku ünitesinde bir gece yatırılarak yapılan polisomnografide (PSG) apne-hipopne indeksinin (AHI) 5 'in üzerinde olduğunun gösterilmesiyle OUAS tanıs1 konmaktadır (www.toraks.org.tr.library). Uyku esnasında üst solunum yolu açıklığını değiştiren faktörler uyku apne sendromu gelişiminde rol alan faktörlerdendir. Kısa ve kalın boyun yapısı, yaşlılık, cinsiyetin erkek olması, alkol ve sedatif ilaç kullanımı, obezite, sigara kullanımı, kraniyofasiyal bozukluklar (retrognati, mikrognati), bu faktörlerdendir (Strauss ve Browner, 2000). OUAS yalnız apne ve desatürasyon ile seyreden bir solunum hastalığı olarak değerlendirilmemelidir. Olaya enflamasyon da eşlik eder ve bu nedenle sistemik etkileri olan bir hastalıktır (Pack ve Gislason, 2009). OUAS kardiyovasküler sistemi etkileyen önemli morbidite ve mortalite nedenlerinden biridir. Atriyalfibrilasyon, hipertansiyon, ani ölüm, kalp yetmezliği, inme ve iskemik kalp hastalığı gibi kardiyovasküler komplikasyonlara sebep olmaktadır (McNicholas ve Bonsigore, 2007). OUAS'de meydana gelen kardiyovasküler hadiselerin mekanizması tam olarak netleşmemiştir. En çok üzerinde durulan mekanizma, uyku esnasında oluşan hipoksi- reoksijenizasyon döngüsü ve arousalların sempatik aktivitede artışa neden olması ile endotel disfonksiyonu, oksidatif stres ve enflamasyonun geliştiği, hiperkoagülabilitenin tetiklendiğidir. Gece oluşan desatürasyon ve reoksijenizasyon döngüleri reperfüzyon hasarı oluşturarak proenflamatuvar sitokinlerin salgılanmasını başlatır. Bunun sonucunda sistemik enflamasyon ve hiperkoagülabilite başlamış olur (Flemons ve ark., 1999; Perlstein ve ark., 2009). Trombositler inflamasyon bölgelerine göç ederek tromboz, inflamasyon ve aterogenez arasında ilişki oluşturur (Kanbay ve ark., 2013). Ortalama trombosit hacmi (OTH), EDG (Eritrosit Dağılım Genişliği) trombosit dağılım aralığı (TDA) rutin kan tetkiklerinde yer almasına rağmen sıklıkla klinisyenler tarafından gözden kaçan, trombosit aktivasyonunu ve yapımını gösteren biyobelirteçlerdir (Varol ve ark., 2011). Ortalama trombosit hacmi artışı ile koroner arter hastalığı, kronik obstruktif akciğer hastalığı, serebrovasküler hastaliklar ve diyabetes mellitus gibi sistemik enflamatuar yanıtın eşlik ettiği hastalıklar arasında anlamlı ilişki olduğu daha önceki çalışmalarda saptanmıştır (Papanas ve ark., 2004; Shen ve ark., 2009). Bu çalışmada uyku ünitemizde takip edilen OUAS tanısı almış hastalarda hastalığın ağırlığı ile OTH, EDG, TDA değerleri arasındaki ilişkiyi değerlendirilmesini, kardiyovasküler hastalığı ve risk faktörü bulunan OUAS tanılı hastaları basit bir yöntem ile saptayarak erken tanı ve komorbiditeler açısından etkin tedaviye yönlendirilmesini amaçladık.

\section{MATERYAL ve METOT}

Çalışmamız için Van Yüzüncü Yıl Üniversitesi Girişimsel Olmayan Etik Kurulundan 12/02/2021 tarih ve 2021/05-04 karar numarası ile onay alınmıştır. Çalışmamızda üniversitemizin Gögüus Hastalıkları 
Uyku Ünitesi'nde polisomnografi (PSG) yapilan 140 hastanin kayıtları, retrospektif olarak değerlendirildi. Çalışmaya, 18-80 yaş aralığındaki hastalar dahil edildi. PSG kayıtları Amerikan Uyku Tibbı Akademisi kriterlerine göre 30 saniyelik epoklarla skorlandı (Iber ve ark., 2007). En az altı saat olmak üzere sertifikalı uyku teknikeri tarafından video görüntüleri ve değerleri kaydedildi. Nazal hava akımının en az 10 saniye boyunca izlenmemesi apne, \%50 oranında düşme ve en az \%3 oksijen satürasyonunda azalma ya da arousal gelişmesi ve yine soluk genliğinde en az 10 saniye \%30'dan fazla düşme ve oksijen satürasyonunda \%4'lük düşme hipopne olarak tanımlandı. Hastanın uyuduğu saat başına düşen toplam apne ve hipopnelerin sayısı AHI olarak tanımlandı. AHI 5 ve üzerinde olan hastalara OUAS tanısı konuldu PSG sonuçlarına göre dört gruba ayrıldı: kontrol grubunu AHI'si 5'in altında olan olgular, hafif OUAS grubunu 5-15 arasinda olan olgular, orta OUAS grubunu 15-30 olan olgular ve ağır OUAS grubunu AHİ 30'un üzerinde olan olgular oluşturdu (ICSD-2, 2005).

Hastaların başvuruları sırasında rutin olarak istenen tam kan sayımı sonuçlarından EDG, OTH ve TDA parametreleri kaydedildi. Yaş, cinsiyet ve vücut kitle indeks (BMI) gibi demografik özellikler kaydedildi. Vücut kitle indeksi (VKİ), hastanın ağırlığ1 $(\mathrm{kg}) /[$ boy $(\mathrm{m})] 2$ olarak hesaplandı. Boyun çevresi ölçümü; krikotiroid membran hizasından yere paralel ölçülerek yapıldı. Sigara içme durumu, mevcut kronik hastalıkların, ilaçların ve alışkanlıkların varlığı uyku çalışmasından önce kaydedildi. Diyabetes mellitus varlığ 1 (DM), hipertansiyon (HT) veya sigara içme öyküsü kardiyovasküler risk faktörü olarak kabul edildi. Daha önce bir doktor tarafından tanı almış ve diyet tedavisi, oral antidiyabetik veya insülin tedavisi kullanan hastalar Diyabetes mellitus hastas1, antihipertansif tedavi almakta olan hastalar Hipertansiyon hastası olarak tanımlandı. Kalp yetmezliği, koroner arter hastalığı ve aritmi tanılı hastalar Kardiyovasküler hastalık grubunu oluşturdu ve bu hastalar antiagregan, antiiskemik, betabloker, ACE inhibitörü, anjiotensin reseptör blokeri ya da kalsiyum kanal blokeri kullanmaktaydi.

Psikiyatrik nedenlere bağlı uyku bozukluğu ve narkolepsi tanısı almış olan, santral uyku apnesi saptanan, kas gevşetici kullanan, 18 yaşın altında olan, karaciğer veya böbrek hastalığı, kronik alkolizm, malignite, hipertiroidizm veya hipotiroidizm, inflamatuar bağırsak hastalıkları, inflamatuar bağ dokusu bozuklukları, astım, lösemi, anemi veya miyelodisplastik sendrom tanılı hastalar çalışma dışı bırakıldı.

\section{İstatistiksel Analiz}

Tüm istatistiksel analizler Statistical Package for the Social Sciences for Windows v20.0 (SPSS Inc., Chicago, IL, ABD) kullanılarak yapıldı. Sürekli değişkenler için tanımlayıcı istatistikler Ortalama, Standart Sapma, Minimum ve Maksimum değer olarak ifade edildi. Kategorik değişkenler Sayı ve Yüzde olarak ifade edildi. Sürekli değişkenler için grup ortalamalarını karşılaştırmak için Student t-testi ve Tek Yönlü Varyans Analizi (ANOVA) kullanıldı. Varyans analizinin ardından farklı grupları belirlemek için Duncan testi kullanıldı.

Değişkenler arasındaki ilişkiyi belirlemek için gruplarda ayrı ayrı Pearson korelasyon katsayıları hesapland1. Gruplar ve kategorik değişkenler arasındaki ilişkiyi belirlemek için ki-kare testi kullanıld1. 0.05'ten küçük bir p değeri, istatistiksel anlaml1lığ

\section{BULGULAR}

140 hastanın dahil edildiği çalışmada hastalar 18-78 yaş arasındaydı. Hastaların ortalama yaşı 47,7 idi ve \% 66,4 ü erkekti. AHİ değerlerine göre hastalar Grup A( AHIं<5; n: 31,\%22,1), Grup B (AHI): 5-14,9; n: 32, \%22,8, Grup C(AHI: 15-30;n: 31, \%22,1), Grup D(AHI: >30;n: 46, \%32,8 ) olarak dörde ayrildı. Gruplar kıyaslandığında, yaş ortalamasının $50,5 \pm 14,2$ ile ağır OUAS grubunda en fazla olduğu izlendi. Vücut kitle indeksi ortalaması (VKİ) 31,7 idi. VKİ, kontrol grubunda en düşükken $(28,8 \pm 4,9)$ ağır OUAS'lı grupta en yüksek olduğu $(34,8 \pm 8,8)$ izlendi. 
Ağır OSAS grubunda BMI istatistiksek olarak anlamlı oranda artmıştı $(\mathrm{p}<, 001)$.

Çalışma grubuna ait klinik özellikler ve laboratuvar parametreleri Tablo 1' de özetlenmiştir.
Ortalama Oksijen saturasyonu ve en düşük Oksijen saturasyonu gruplar arasinda istatistiksel olarak anlamlı şekilde farklıydı. Ortalama Oksijen saturasyonu ve en düşük Oksijen Saturayonu değeri ağır OUAS grubunda en düşük düzeydeydi $(\mathrm{p}<, 05, \mathrm{p}<, 001)$.

Tablo 1.Çalışma Grubuna ait dermografik ve laboratuvar parametreler.

\begin{tabular}{llllll}
\hline \hline & $\begin{array}{l}\text { Grup A } \\
\text { (n:31) }\end{array}$ & $\begin{array}{l}\text { Grup B } \\
\text { (n:32) }\end{array}$ & $\begin{array}{l}\text { Grup C } \\
\text { (n:31) }\end{array}$ & $\begin{array}{l}\text { Grup D } \\
\text { (n:46) }\end{array}$ & p \\
\hline Yaş (y) & $46 \pm 17$ & $47 \pm 14$ & $46 \pm 11$ & $51 \pm 14$ &, 425 \\
Cinsiyet, erkek n (\%) & $20(\% 64,5)$ & $21(\% 65,6)$ & $26(\% 83,9)$ & $26(\% 56,5)$ &, 097 \\
VKİ (kg/m2) & $28,8 \pm 4,9$ & $31,9 \pm 7$ & $29,7 \pm 4,4$ & $34,8 \pm 8,8$ &, 001 \\
Sigara & $12(\% 38,7)$ & $10(\% 31,3)$ & $15(\% 48,4)$ & $22(\% 47,8)$ &, 422 \\
Hipertansiyon & $6(\% 19,4)$ & $6(\% 18,8)$ & $8(\% 25,8)$ & $21(\% 45,7)$ &, 025 \\
Diyabet & $5(\% 16,1)$ & $6(\% 18,8)$ & $6(\% 19,4)$ & $16(\% 34,8)$ &, 181 \\
KVH & $5(\% 16,1)$ & $7(\% 21,9)$ & $3(\% 9,7)$ & $15(\% 33,3)$ &, 078 \\
TDA (fl) & $16,2 \pm 2,4$ & $16,9 \pm 2$ & $16 \pm 2,5$ & $17 \pm 1,5$ &, 125 \\
OTH (fl) & $8,6 \pm 0,8$ & $8,8 \pm 1,1$ & $8,1 \pm 1$ & 8,4 &, 084 \\
EDG (\%) & $14,8 \pm 3,9$ & $14,7 \pm 2,2$ & $14,2 \pm 1,9$ & $14,7 \pm 2,2$ &, 827 \\
Hb (g/dl) & $15,3 \pm 1,1$ & $14,9 \pm 2,1$ & $15 \pm 1,9$ & $14,8 \pm 1,7$ &, 724 \\
Htc (\%) & $46,6 \pm 3,7$ & $44,5 \pm 7,6$ & $45,7 \pm 6,1$ & $45,5 \pm 5,8$ &, 600 \\
\hline \hline
\end{tabular}

VKI: Vücut kitle indeksi, KVH: Kardiyovasküler Hastalıklar, TDA: Trombosit dağılım aralığı, OTH: Ortalama trombosit hacmi, EDG: Eritrosit dağılım genişliği, Hb: Hemoglobin, Htc: Hematokrit

lendi. ODİ değeri ağır OUAS grubunda en yüksek ODİ (Oksijen Desaturasyon İndeksi) Grup A'da değerdeydi ve bu farklılık istatistiksel olarak an-

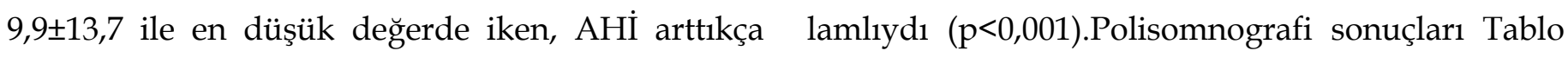
giderek arttığ $19,8 \pm 10,3 ; 19,5 \pm 18,3 ; 41,0 \pm 24,0)$ belir- 2 'de özetlenmiştir.

Tablo 2.Çalışma grubuna ait polisomnografi bulguları

\begin{tabular}{llllll}
\hline \hline & $\begin{array}{l}\text { Grup A } \\
\text { (n:31) }\end{array}$ & $\begin{array}{l}\text { Grup B } \\
\text { (n:32) }\end{array}$ & $\begin{array}{l}\text { Grup C } \\
\text { (n:31) }\end{array}$ & $\begin{array}{l}\text { Grup D } \\
\text { (n:46) }\end{array}$ & p \\
\hline Evre 1(\%) & $10,7 \pm 10,5$ & $10,3 \pm 8,5$ & $10,8 \pm 6,5$ & $12,8 \pm 9,3$ &, 580 \\
Evre 2(\%) & $46,8 \pm 20,4$ & $44,6 \pm 18,1$ & $48,3 \pm 19,9$ & $46,6 \pm 20,5$ &, 909 \\
Evre 3(\%) & $33,1 \pm 16,5$ & $34,4 \pm 16,1$ & $30,5 \pm 17,8$ & $31,2 \pm 20,3$ &, 807 \\
REM(\%) & $10 \pm 10,6$ & $10,3 \pm 7,1$ & $11,6 \pm 10$ & $9,6 \pm 11,5$ &, 861 \\
UE(\%) & $74,2 \pm 20,4$ & $77,7 \pm 15,3$ & $78,1 \pm 17,5$ & $80,1 \pm 15,4$ &, 532 \\
Ortalama O2 sat & $90,9 \pm 5$ & $90,2 \pm 6$ & $90,1 \pm 4,5$ & $87,1 \pm 6,4$ &, 009 \\
Minimum O2 sat & $83,6 \pm 8,1$ & $79,4 \pm 10,4$ & $78,3 \pm 7,8$ & $70,4 \pm 11,9$ &, 001 \\
ODİ & $9,9 \pm 13,7$ & $9,8 \pm 10,3$ & $19,5 \pm 18,3$ & $41 \pm 24$ &, 001 \\
\hline \hline
\end{tabular}




\section{TARTIŞMA}

OUAS her geçen gün daha çok kişiye tanı konulan, kardiyovasküler hastalıklar ve inme gibi pek çok komorbidite ve komplikasyonlara sebep olabilen bir hastalıktır (Azagra-Calero ve ark., 2012). Obstruktif uyku apne sendromu, uyku esnasında üst hava yolunun obstrüksiyonu ile solunumun döngüler halinde engellenmesidir (ICSD-2, 2005). OUAS siklıkla 40-65 yaşlarında ve erkeklerde saptanmaktadır (Köktürk, 2000). Çalışmamızda yaş ortalaması 47,7 ve erkeklerde görülme oranı \% 66.4 olarak saptanmiştır.

OUAS'lı erkek hastaların yarısından çoğunun obez olduğu, özellikle santral obezitenin ön planda olduğu bildirilmiştir (Weiss ve Goodnough, 2005). VKİ (Vücut kitle indeksi) $29 \mathrm{~kg} / \mathrm{m} 2$ üzeri hesaplananların obez olarak alındığı bir çalışmada, hafif OUAS' da \%69, orta ve ağır OSAS'da \%77 oranında obezite saptanmıştır (Güven ve ark., 2002). Türkiye'de yapılan bir çalışmada OUAS'lı hastanin \%36.9'u fazla kilolu, \%40.5'i ise obez olarak saptanmıştır (Ursavaş ve ark., 2004). Bizim çalışmamızda VKİ ortalaması 31,7'ydi. Grup $A^{\prime}$ da en düşükken $(28,8 \pm 4,9)$ Grup D de en yüksek $(34,8 \pm 8,8)$ düzeydeydi. Çalışmamızda obezite şiddeti ile doğru orantılı olarak AHI'nin arttığ1 ve satürasyon değerlerinin düştüğünü gördük. Benzer bulguların elde edildiği başka çalışmalar da mevcuttur (Kirişoğlu ve Köktürk, 2002).

Toplumda en sık görülen kardiyovasküler komplikasyon hipertansiyondur. OUAS hastalarında görülme oranı \%30 ile \%60 arasındadır (Phillips, 2005). Başarılı şekilde tedavi edilen OUAS hastalarında hem gece hem gündüz ölçülen kan basınçlarında düşme sağlandığı gösterilmiştir. İdiyopatik HT tanılı hastaların ise gerçekte henüz tanı konulamamış OUAS olguları olduğu düşünülmektedir (Silverberg ve ark., 1997). Bir başka çalışmadaysa OUAS tanısı alan olguların \%45.3'ünde HT varlığ1 bildirilmiştir (Lavie ve ark., 2000). Bizim çalış- mamızda da ağır OUAS grubunda Hipertansiyon görülme oranı diğer gruplardan yüksek ve istatistiksel olarak anlamlı saptanmıştır. OUAS'lı hastalarda pozitif hava yolu basıncı kullanımı ile hipertansiyon kontrolü sağlandığını gösterilen pek çok çalışma bulunmaktadır (Çuhadaroğlu ve Kuzu Okur, 2018).

Çalışmamızda hafif, orta ve ağır OUAS hastalarının ve kontrol grubunun hemogram, hematokrit, TDA, EDG ve OTH değerleri ile gruplar arasında istatistiksel olarak anlamlı farklılık saptanmamıştır. OUAS sonrası ortaya çıkabilecek kardiyovasküler hastalıkları laboratuvar parametreleri ile belirlemeyi amaçlayan birçok çalışma yapılmıştır. OUAS ağırlığı ile OTH'nin yükseldiği ve OUAS' da görülen kardiyovasküler komplikasyonları OTH'yi ölçerek öngörebileceğimiz belirtilmiştir (Kondo ve ark., 2011, Erden ve ark., 2013). OUAS'de OTH artış1nın mekanizması, uykuda meydana gelen hipoksi ve sempatik uyarıların enflamasyonu tetiklediği ve trombositleri aktive ettiği şeklinde açılanmıştır (Dunleavy ve ark., 2005). OTH ile hastaların kalp hızı değişkenliği arasında korelasyon olduğunu gösteren bir çalışmada ise OUAS ağırlığı ile OTH arasında ilişki saptanmamıştır (Akyüz ve ark. 2014). Bir başka çalışmada sürekli pozitif hava yolu basınc1 (CPAP) tedavisi ile hastalarda OTH' de anlamlı bir düşüş olduğu bildirilmiş ve OTH düzeyinin, $\mathrm{CPAP}^{\prime}$ in kalp üzerine koruyucu etkisini göstermede kullanılabileceği sonucuna varılmıştır (Esen ve ark., 2015). Kıvanç ve arkadaşlarının yaptığı çalışmada ise OTH ile OSAS şiddeti arasında herhangi bir ilişkinin bulunmadığ1 gösterilmiştir (Kıvanç ve ark., 2018).

Çalışmaların çoğunda OUAS'de hastalık seyrini izleme TDA, EDG ve OTH'nin yüksekliğinin yol gösterici olabileceği düşünülmektedir. Ancak bizim çalışmamızda belirgin bir ilişki saptanmadı.

Uyku sırasında hastada oluşan desatürasyon ve hemen arkasından gelen reoksijenizasyon atakları reperfüzyon hasarına neden olur. Böylelikle 
proenflamatuvar sitokinler salınır. OUAS şiddeti ve hipoksi süresi arttıkça oluşan sitokin miktarı artar. Sistemik enflamasyonun kemik iliğini etkilemesi ile beraber eritropoez etkilenir, eritrosit yıkımı artar, eritrositlerde boyut farklılığ olarak EDG artar (Jack ve Gislason, 2009). Bizim çalışmamızda ise EDG ile ortalama oksijen saturasyonu arasında pozitif ve minimum oksijen saturasyonu arasinda negatif korelasyon vard1. Kardiyovasküler hastalıklar için EDG artışının risk faktörü olduğunu ortaya koyan birkaç çalışma vardır (Dabbah ve ark., 2010). OUAS'lı hastaları kontrol grubu ile karşılaştıran bir başka çalışmada hasta popülasyonunda EDG'nin daha yüksek olduğu bildirilmiştir (Özsu ve ark., 2012). Bir çalışmada EDG artışı ile hastalığın ağırlığı ve AHİ'nin pozitif korelasyon gösterdiği, bir başka çalışmada da ağır OUAS'li hastaların EDG değerini kontrol grubuna göre yüksek saptandığı, EDG ile AHİ arasında pozitif, minimum oksijen satürasyonları arasında ise negatif korelasyon saptandığı bildirilmiştir (Karakaş ve ark., 2013).

Sonuç olarak, OUAS'da hastalığın takibi, gelişebilecek komplikasyonların önceden öngörülüp, erken tedavi altına alınabilmesi bu hastalığın yükünü hafifletecektir. Bu nedenle kullanılabilecek basit, ucuz, kolay ulaşılabilir bir yöntem olan tam kan sayımında bakılandeğerler hastalığın ağırlığı ve komplikasyonlar açısından yol gösterici olabilir. Çalışmamiz sonucunda TDA, EDG ve OTH ile gelişimi olan kardiyovasküler komplikasyonlar arasında istatistiksel olarak bir fark bulamadık. Ancak bu konu her geçen gün tanı konma oranınınyükseldiği, hasta sayısının arttığı OUAS' da özellikle daha geniş hasta sayıları ile, prospektif planlanacak, komplikasyonlar henüz gelişmeden hastayı uzun süre takibe al1nacak ve tabiki CPAP tedavi sonrasını da içeren gelecekteki çalışmalar ile daha net aydınlanacaktır.

\section{Çıkar Çatışması}

Yazarlar çıkar çatışması olmadığını beyan eder.

\section{Etik Kurul onayı:}

Van Yüzüncü Yıl Üniversitesi Girişimsel Olmayan Etik Kurulundan 12/02/2021 tarih ve 2021/05-04 karar numarası ile onay alınmıştır

\section{KAYNAKLAR}

Akyüz A, Akkoyun DÇ, Oran M, Değirmenci $H$, Alp R. Mean platelet volume in patients with obstructive sleep apnea and its relationship with simpler heart rate derivatives. Cardiol Res Pract 2014;454701.

American Academy of SleepMedicine. ICSD-2: The International Classification of SleepDisorders. Diagnostic and Coding Manual, 2005; Published 2 ed. AASM, Westchester, Illinois.

Azagra-Calero E, Espinar-Escalona E, BarreraMora JM, Llamas-Carreras JM, Solano-Reina E. Obstructive sleep apnea syndrome (OSAS). Med Oral Patol Oral CirBucal 2012;17(6):925-9.

Çuhadaroğlu Ç, Kuzu Okur H. Hipertansiyon ve uykuda solunum bozuklukları. Turkiye Klinikleri J Cardiol-Special Topics 2018;11(1):37-40.

Dabbah S, Hammerman H, Markiewicz W, Aronson, D. (2010). Relation between red cell distribution width and clinical out comes after acute myocardial infarction. Am J Cardiol 2010; 105:312-7.

Dunleavy M, Dooley M, Cox D, Bradford A. Chronic intermittent asphyxia increases platelet reactivity in rats. Exp Physiol 2005;90:411-6.

Erden EŞ, Yengil E, Tuncel E, Bilgiç HY, Demirköse $\mathrm{M}$, Motor S ve ark. Obstrüktif uyku apne sendromu ile ortalama trombosit hacmi arasındaki ilişkinin incelenmesi. J Clin Exp Invest 2013; 4:492-6.

Esen E, Özdoğan F, Özel HE, Yılmaz Z, Yüce T, Başer S. T1kayıcı uyku apne sendromunda ortalama trombosit hacminin hastalık şiddetinde rolü var midır? Kulak Burun Bogaz Ihtis Derg 2015;25(6):343-5.

Flemons WW, Buysse AD, Redline S. Sleep-related breathing disorders in adults: recommendations for syndrome definition and measurement 
techniques in clinical research. Sleep 1999;22:667-89.

Güven SF, Çiftçi TU, Çiftçi B, Şipit T. Obstrüktif uyku apne sendromunda risk faktörleri. Toraks Derneği 5. Yıllık Kongresi Özet Kitabı, 2002. pp-614.http://www.toraks.org.tr/library.

Iber C, Ancoli-Israel S, Chesson A. American Academy of Sleep Medicine. The AASM manual for the scoring of sleep and associated events: rules, terminology and technical specifications, 2007;1 st ed. Westchester, IL.

Jack AI, Gislason T. Obstructive sleep apnea and cardiovascular disease: a perspective and future directions. Prog Cardiovasc Dis 2009;51:434-51.

Kanbay A, Tutar N, Kaya E, Büyükoğlan H, Özdoğan N, Oymak F, et al. Mean platelet volume in patients with obstructive sleep apnea syndrome and its relationship with cardiovascular diseases. Blood Coagul Fibrinolysis 2013; 24:532-6.

Kapsoritakis AN, Koukourakis MI, Sfiridaki A, Potamianos SP, Kosmadaki MG, Koutroubakis IE et al. Mean platelet volume: a useful marker of inflammatory bowel disease activity. Am J Gastroenterol 2001;96:776-81.

Karakaş MS, Er A, Gülcan AR, Altekin RE, Yalçınkaya S, Çilli A. Assesment of red cell distribution width (RDW) in patients with obstructive sleep apnea syndrome. J Turgut Ozal Med Cent 2013;20:208-14.

Kıvanç T, Kulaksızoglu S, Lakadamyalı H, Eyuboglu F. Importance of laboratory parameters in patients with obstructive sleep apnea and their relationship with cardiovascular diseases. J Clin Lab Anal 2018; 32:e22199.

Kirişoğlu C, Köktürk O. Obstrüktif uyku apne sendromunda obezitenin etkileri. Toraks Derneği 5. Yıllık Kongresi Özet Kitabı 2002;pp-058.

Kokturk O, Tatlıcıoğlu T, Kemaloğlu Y, Firat H, Çetin N. Habituel horlaması olan olgularda obstruktif uyku apne sendromu prevalans1. Tuberkuloz ve Toraks 1997; 45:7-11.
Kondo Y, Kuwahira I, Shimizu M, Nagai A, Iwamoto $T$, Kato $S$ et al. Significant relationship between platelet activation and apnea-hypopnea index in patients with obstructive sleep apnea syndrome. Tokai J Exp Clin Med 2011;36:79-83.

Köktürk O. Obstruktif uyku apne sendromu sonuçları. Tüberküloz ve Toraks Derg 2000; 48(3):273-89.

Lavie P, Herer P, Hoffstein V. Obstructive sleep apnea syndrome as a risk factor for hypertension: population study. BMJ 2000; 320:479-82.

Mc Nicholas WT, Bonsigore MR. Sleep apnoea as an independent risk factor for cardiovascular disease: current evidence, basic mechanisms and research priorities. Eur Respir J 2007; 29:156-78.

Ozsu S, Abul Y, Gulsoy A, Bulbul Y, Yaman S, Ozlu, T. Red cell distribution width in patients with obstructive sleep apnea syndrome. Lung 2012; 190:319-26.

Pack AI, Gislason T. Obstructive sleep apnea and cardiovascular disease: a perspective and future directions. Prog Cardiovasc Dis 2009; 51:434-51.

Papanas N, Symeonidis G, Maltezos E, Mavridis G, Karavageli E, Vosnakidis $\mathrm{T}$ et al. Mean platelet volume in patients with type 2 diabetes mellitus. Platelets 2004;15:475-8.

Perlstein TS, Weuve J, Pfeffer MA, Beckman JA. Red blood cell distribution width and mortality risk in a community-based prospective cohort. Arch Intern Med 2009;169:588-94.

Phillips B. Sleep-disordered breathing and cardiovascular disease. Sleep Med Rev 2005; 9(2):131-40.

Shen J, Ran ZH, Zhang Y, Cai Q, Yin HM, Zhou XT, et al. Biomarkers of altered coagulation and fibrinolysis as measures of disease activity in active inflammatory bowel disease: a gender-stratified, cohort analysis. Thromb Res 2009;123(4):604-11.

Silverberg DS, Oksenberg A, Laina A. Sleep related breating disorders are common contribu- 
ting factors to the production of essential hypertension but are neglected, under diagnosed and undertreated. Am J Hypertens 1997;10:1319-25.

Strauss RS, Browner WS. Risk for obstructive sleep apnea. Ann Intern Med 2000;132(9):758-9.

Ursavaş A, Göktaş K, Sütcügil L, Özgen F. Obstruktif uyku apne snedromu olan hastalarda obezite ve kardiyovasküler hastalıkların değerlendirilmesi. Toraks Derg 2004;2:79-83.
Varol E, Ozturk O, Yucel H, Gonca T, Has M, Dogan A et al. The effects of continuous positive airway pressure therapy on mean platelet volume in patients with obstructive sleep apnea. Platelets 2011;22:552-6.

Weiss G, Goodnough LT. Anemia of chronic disease. N Engl J Med 2005;352:1011-23. 